\title{
Taxa de câmbio e exportações líquidas: uma análise para os estados brasileiros
}

\author{
Exchange rate and net exports: an analysis for the brazilian states
}

\author{
Elano Ferreira Arruda (1) \\ Gabriel Martins (2) \\ (1) Universidade Federal do Ceará \\ (2) Universidade Federal do Ceará
}

\begin{abstract}
This paper analyses the short and long run effects of exchange rate devaluation on the net exports, in the trade balance, as well as in the balances of basics and industrial goods for a panel of Brazilian states, making use of Panel Vector Autoregression (PVAR) models and Panel Dynamic Ordinary Least Squares (PDOLS) estimators. The first technique is used to investigate the existence of the J curve phenomenon, and the latter to validate of Marshall-Lerner condition. In all cases, the response of the net exports from that states after an exchange rate devaluation is shown to be positive, thus confirming the MarshallLerner condition. This response is greater for trade balance of industrialized goods. As described by the theoretical model, domestic income presents a negative and statistically robust impact in all net exports considered, while foreign income presents a positive effect. The results still show evidence of the J curve for the total and industrialized goods.
\end{abstract}

\section{Keywords}

net exports, J curve, Marshall-Lerner condition, PVAR, PDOLS.

JEL Codes F10, F31, F41.

\section{Resumo}

Este artigo analisa os impactos de curto e de longo prazo das desvalorizações cambiais sobre as exportações líquidas totais, de básicos e de industrializados para um painel de estados brasileiros a partir da aplicação de modelos Panel Vector Autoregression (PVAR), para testar a ocorrência do fenômeno da curva J, e do Panel Dynamic Ordinary Least Squares (PDOLS), para investigar a validade da condição de Marshall-Lerner. Em todos os modelos considerados a resposta das exportações líquidas dos estados brasileiros a uma depreciação cambial se mostra positiva, validando, portanto, a condição de Marshall-Lerner. Essa resposta é maior para os bens industrializados. Como previsto pela teoria, a renda doméstica apresenta impacto negativo e estatisticamente robusto sobre o saldo comercial, enquanto a renda externa apresenta repercussão positiva. Os resultados indicam a ocorrência da curva J para os totais e os industrializados.

\section{Palavras-chave}

exportações líquidas, curva J, condição de Marshall-Lerner, PVAR, PDOLS.

Códigos JEL F10, F31, F41. 


\section{Introdução}

Em anos recentes, especialmente após o fim do acordo de Bretton Woods, as taxas de câmbio se tornaram fortemente voláteis, em decorrência da adoção do regime de câmbio flutuante. Vários pesquisadores têm voltado seus estudos para avaliar como as políticas cambiais repercutem nas exportações líquidas e de que forma influenciam o crescimento econômico. Ou seja, num ambiente econômico cada vez mais globalizado, o entendimento dessas relações se mostra relevante para os formuladores de política econômica. Nessa perspectiva, discutem-se os aspectos teóricos e a regularidade empírica da chamada curva J e da condição de Marshall-Lerner.

Segundo Bahmani-Oskooee e Brooks (1999), a curva J refere-se à ocorrência de uma depreciação nas exportações líquidas em curto prazo, seguida por um saldo superavitário em longo prazo, em resposta a uma desvalorização cambial. Esse fenômeno seria explicado pela existência, no curto prazo, de uma rigidez relativa em termos de quantum importado e exportado, decorrente de contratos de câmbio (Ramos Filho; Ferreira, 2016). Krugman e Obstfeld (2000) justificam o fenômeno da curva J sob o argumento de que, após uma depreciação cambial, os valores das exportações e importações ainda representam contratos celebrados com base na antiga taxa de câmbio real, refletindo no aumento do valor das importações em termos de bens domésticos e, além disso, a persistência de hábitos e costumes e a defasagem da tomada de decisão por parte dos agentes econômicos também são apresentados como fatores explicativos desse fenômeno.

A condição de Marshall-Lerner preconiza que somente haverá uma melhora nas exportações líquidas em resposta a uma depreciação cambial se, e somente se, o volume das exportações e importações for elástico em relação à taxa de câmbio real (Bahmani-Oskooee; Fariditavana, 2015; Moura; Da Silva, 2005).

Especificamente sobre a economia brasileira, autores como Sonaglio, Scalco e Campos (2010), Mortatti, Miranda e Bacchi (2011), Scalco, Carvalho e Campos (2012) e Ramos Filho e Ferreira (2016) apresentaram contribuições recentes.

Os primeiros avaliam a ocorrência do fenômeno da curva J e da condição de Marshall-Lerner na relação bilateral entre Brasil e Estados Unidos, entre 1994 e 2007, com vetores de correção de erros (VEC), levando em 
consideração 21 setores. Os resultados indicam a ocorrência do fenômeno da curva J apenas para os setores de indústrias diversas e óleos vegetais, enquanto a condição de Marshall-Lerner se mostra válida para seis setores: borracha, calçados, equipamentos eletrônicos, madeira e mobiliário, peças e outros veículos e artigos de vestuário. Mortatti, Miranda e Bacchi (2011) promovem análise semelhante, considerando o comércio Brasil-China, e observam a ocorrência do fenômeno da curva J para as commodities agrícolas e para os produtos industrializados.

Em estudo sobre o comércio da agropecuária do Brasil com o resto do mundo, Scalco, Carvalho e Campos (2012) rejeitam a hipótese da ocorrência do fenômeno da curva J e confirmam a validade da condição de Marshall-Lerner. Ramos Filho e Ferreira (2016) estudam o comércio entre o Brasil e o resto do mundo considerando 19 setores, com dados anuais entre 1996 e 2012 e modelos ARDL. Os autores observam evidências para a curva J em cinco dos setores analisados.

Portanto, apesar da importância dessa temática e do crescimento recente da quantidade de estudos sobre o tema, ainda não há um consenso sobre a ocorrência e a regularidade desses fenômenos na economia brasileira, sobretudo numa perspectiva regional. Nesse sentido, Rickman (2010) argumenta que os modelos econômicos regionais são construídos a partir de seus congêneres nacionais e que técnicas macroeconométricas têm sido subutilizadas em economia regional. $O$ autor adverte ainda que, em modelos regionais, é possível mitigar problemas associados ao viés de agregação de dados nacionais, sobretudo em países de dimensões continentais, com grandes disparidades e peculiaridades regionais. No Brasil, as diversas políticas cambiais adotadas desde a década de 1990, a profunda diversidade/ disparidade regional entre seus estados e a crescente abertura comercial oferecem uma boa oportunidade quanto à análise da relação entre balança comercial e variações na taxa de câmbio (Sonaglio, Scalco; Campos, 2010). O presente trabalho se propõe a enveredar nessa direção, ao elaborar um estudo para um painel de estados brasileiros, investigação ainda não realizada na literatura nacional.

Os primeiros esforços observados nesse enfoque são encontrados nos estudos de Moraes et al. (2015) e Arruda e Martins (2016), com exercícios empíricos para os estados do Rio Grande do Sul e Ceará, respectivamente. Ambos utilizam os vetores de correção de erros (VEC). Os primeiros observam a ocorrência da curva J e a não validade da condição de Marshall- 
-Lerner, enquanto os últimos encontram evidências positivas para ambas as relações no segmento de bens industrializados.

Portanto, o presente trabalho contribui para a literatura com a análise empírica das relações de curto e longo prazos entre a taxa de câmbio real e as exportações líquidas ${ }^{1}$ para um painel com 10 estados brasileiros (Bahia, Pernambuco, Ceará, São Paulo, Rio de Janeiro, Minas Gerais, Espírito Santo, Rio Grande do Sul, Paraná e Santa Catarina) contendo informações mensais entre janeiro de 1999 e dezembro de 2015; ou seja, verificar-se-á a ocorrência do fenômeno da curva J e da condição de Marshall-Lerner para a balança comercial dos estados brasileiros utilizando-se o arcabouço Panel Dynamic Ordinary Least Squares (PDOLS), para estimar as relações de longo prazo, e um Panel Vector Autoregression (PVAR), para extrair as relações de curto prazo, a partir das funções de impulso resposta (FIR). Além disso, esta análise também será executada em nível desagregado para produtos básicos e industrializados.

Vale ressaltar, conforme dados da Secretaria de Comércio Exterior do Ministério do Desenvolvimento, Indústria e Comércio Exterior (SECEX/ MDIC), que entre 1999 e 2015 os 10 estados considerados neste estudo foram responsáveis, em média, por $86 \%$ das relações comerciais da economia brasileira, evidenciando, assim, sua representatividade para o exame proposto.

Assim, o estudo inova por apresentar uma investigação dessa natureza, levando em consideração as heterogeneidades regionais via modelos aplicados em painéis de dados, além de fazer uso do PDOLS para testar a condição de Marshall-Lerner, uma técnica ainda não empregada em estudos nessa área, e examinar o fenômeno da curva J a partir das FIRs extraídas de um PVAR estimado, com efeitos fixos.

Além desta introdução, o trabalho possui mais cinco seções. A seção dois apresenta os aspectos teóricos sobre a curva J e a condição de Marshall-Lerner. Em seguida, apresenta-se uma revisão da literatura empíri-

1 Os demais estados brasileiros não foram incluídos na análise, em virtude da ausência de dados mensais de uma proxy de renda doméstica. Vale destacar que o uso de dados mensais se mostra adequado, uma vez que se pretende analisar os efeitos de curto prazo da taxa de câmbio real sobre as exportações líquidas.

2 Os demais estados brasileiros não foram incluídos na análise, em virtude da ausência de dados mensais de uma proxy de renda doméstica. Vale destacar que o uso de dados mensais se mostra adequado, uma vez que se pretende analisar os efeitos de curto prazo da taxa de câmbio real sobre as exportações líquidas. 
ca com estudos nacionais e internacionais. A seção quatro se reserva à exposição dos aspectos metodológicos, qual seja, a descrição da base de dados e da estratégia econométrica. A análise e discussão dos resultados é realizada a seguir e, por fim, são tecidas as considerações finais do estudo.

\section{Aspectos teóricos}

Para explicar a relação entre a taxa de câmbio e a balança comercial, Bickerdike (1920), Marshall (1923), Lerner (1944), Robinson (1947) e Metzler (1948) desenvolveram um modelo baseado nas elasticidades das funções oferta e demanda. $O$ modelo pressupõe a existência de dois mercados: o mercado externo e o mercado interno. No primeiro, o país local exerce a demanda por bens estrangeiros, sendo estes ofertados pelo resto do mundo; enquanto no segundo ocorre o inverso, isto é, o país local oferta os bens produzidos internamente, para que sejam demandados pelo resto do mundo.

Nessas condições, uma desvalorização cambial provoca uma retração na oferta do resto do mundo e uma expansão da oferta doméstica, estimulada em parte pelo aumento da demanda externa. Na economia doméstica, o valor das exportações tende a aumentar devido ao barateamento de seus produtos em moeda externa, enquanto o valor das importações pode aumentar ou reduzir, dependendo da elasticidade-preço da oferta, tornando o efeito de uma desvalorização cambial ambíguo (Moura; Da Silva, 2005).

Portanto, nesse modelo, a condição de suficiência para a ocorrência de superávit na balança comercial em resposta a uma depreciação cambial, denominada condição Bickerdike-Robinson-Metzler (BRM), é a de que a derivada desta em relação à taxa de câmbio seja positiva.

Nos moldes de Arruda, Castelar e Martins (2019), o modelo BRM pode ser analisado a partir da relação que explicita o saldo da balança comercial:

$$
B=P_{X} X-P_{M} M
$$

em que: $M, X$ : importações e exportações efetuadas pela economia doméstica, respectivamente; $P M, P X$ : preços das importações e exportações em moeda doméstica, respectivamente; 
O modelo BRM fornece uma condição geral ${ }^{3}$ que determina a variação nos saldos comerciais a partir da diferenciação da equação (1) e da utilização dos conceitos de elasticidades de demanda por importações e de elasticidade de oferta de exportações; ou seja, a relação que explicita a variação absoluta nos saldos comerciais, partindo de um equilíbrio inicial $(\mathrm{B}=0)$, é dada por:

$$
d B=P_{X} X\left[\frac{(1+\varepsilon) \eta^{*}}{\varepsilon+\eta^{*}}-\frac{(1-\eta) \varepsilon^{*}}{\varepsilon^{*}+\eta}\right] \frac{d e}{e}
$$

em que, e: taxa de câmbio nominal (preços em moeda doméstica/preço em moeda estrangeira); $\eta$ : elasticidade compensada da demanda de importações domésticas; $\eta$ : elasticidade compensada da demanda de importações do resto do mundo; $\varepsilon$ : elasticidade compensada da oferta de exportações domesticas; $\varepsilon^{*}$ : elasticidade compensada da oferta de exportações do resto do mundo.

No modelo BRM, a condição suficiente para que ocorra um resultado superavitário nos saldos comerciais, numa economia após uma depreciação cambial, é dada por:

$$
\frac{(1+\varepsilon) \eta^{*}}{\varepsilon+\eta^{*}}>\frac{(1-\eta) \varepsilon^{*}}{\varepsilon^{*}+\eta}
$$

A condição de Marshall-Lerner é uma situação particular da relação acima, quando se considera que as elasticidades-preço da oferta dos bens exportados e importados da economia doméstica tendem ao infinito. Ou seja, nesse cenário, a soma das elasticidades-preço das demandas interna e externa será maior que um, ${ }^{4}$ isto é:

$$
\lim _{\substack{\varepsilon \rightarrow \infty ; \\ \varepsilon^{*} \rightarrow \infty}} \frac{(1+\varepsilon) \eta^{*}}{\varepsilon+\eta^{*}}>\lim _{\substack{\varepsilon \rightarrow \infty ; \\ \varepsilon^{\rightarrow} \rightarrow \infty}} \frac{(1-\eta) \varepsilon^{*}}{\varepsilon^{*}+\eta} \rightarrow \eta^{*}>1-\eta \rightarrow\left(\eta+\eta^{*}\right)>1
$$

3 Para verificação dessas relações e a derivação da condição geral do modelo BRM, ver Arruda, Castelar e Martins (2019).

4 Nessas circunstâncias, o coeficiente estimado do efeito da taxa de câmbio real sobre as exportações líquidas deverá ser positivo e estatisticamente significante, para confirmar a validade da condição de Marshall-Lerner. 
Uma abordagem complementar à das elasticidades é a abordagem da absorção, ${ }^{5}$ que considera os efeitos da desvalorização cambial, não somente nos preços relativos e na balança comercial, mas também sobre a renda e a absorção.

Isto posto, após uma desvalorização cambial, os agentes do país doméstico podem: a) demandar produtos domésticos no lugar de produtos estrangeiros, devido ao seu encarecimento em moeda doméstica; b) dado um aumento na renda interna, aumentar sua demanda por produtos estrangeiros quanto maiores forem a propensão marginal a consumir e a elasticidade da oferta externa por importações. O efeito a) é denominado efeito substituição e b) efeito renda. Em geral, a abordagem da absorção explica que uma desvalorização cambial tende a deteriorar os termos de troca, mas isso não implica déficit na balança comercial. Para que haja melhora na balança comercial, é necessário que o efeito substituição seja maior que o efeito renda (Moura; Da Silva, 2005).

Além disso, discute-se a ocorrência da curva J, que é um fenômeno em que, após uma desvalorização cambial, ocorre uma deterioração na balança comercial no curto prazo, e superávit, em longo prazo. Sob a ótica da absorção, a curva J pode ser definida como: o efeito renda é dominante no curto prazo, enquanto no médio e longo prazos predomina o efeito substituição e, como consequência, o gráfico da resposta da balança comercial a uma depreciação cambial ao longo do tempo tem o formato da letra J. Vale destacar que a condição de Marshall-Lerner permanece válida nesse processo, pois o superávit, embora não se manifeste de imediato, ocorre no equilíbrio em longo prazo (Lobo, 2007; Moura; Da Silva, 2005).

\section{Evidências empíricas}

\subsection{Evidências internacionais}

Bahmani-Oskooee e Brooks (1999) utilizam dados trimestrais, entre 1973 e 1996, e modelos ARDL para avaliar a validade da curva J e da condição

5 Apesar de serem versões teórico-analítica distintas, ambas buscam explicar o mesmo fenômeno; qual seja, a ocorrência de déficits nas exportações líquidas em curto prazo, seguida por superávits em longo prazo após uma desvalorização cambial. Logo, é importante destacar que essas abordagens são complementares e, portanto, não excludentes. 
de Marshall-Lerner no comércio dos EUA com os demais países do G-7. Em todos os casos analisados, os autores observam a validade da condição de Marshall-Lerner e a não ocorrência da curva J. Na mesma linha, Boyd, Caporale e Smith (2001) empregam o arcabouço ARDL com dados trimestrais entre 1975 e 1976 para oito países industrializados. ${ }^{6}$ Os resultados indicam certa regularidade desses fenômenos para os países analisados.

Narayan (2004) analisa a validade da curva J na balança comercial da Nova Zelândia com dados anuais de 1970 a 2002 e modelos ARDL, FM-OLS e DOLS. Seus resultados indicam a ocorrência do fenômeno. Narayan e Narayan (2004) fazem investigação análoga para as Ilhas Fiji, usando dados anuais de 1970 a 2000 e modelos ARDL. Os autores encontram evidência em favor da ocorrência da curva J.

Ainda com modelos ARDL e dados mensais entre janeiro de 1991 a agosto de 2002, Ardalani e Bahmani-Oskooee (2007) testam esses fenômenos para 66 setores da economia americana. Os resultados indicam a ocorrência da curva J em seis setores, e a validade da condição de Marshall-Lerner em 22 deles.

A fim de observar a existência da curva J entre Canadá e 20 de seus parceiros comerciais, Bahmani-Oskooee, Goswami e Talukdar (2008) fazem uso de modelos ARDL com dados trimestrais de 1973 a 2001. Os resultados confirmam a validade do fenômeno em 11 das 20 balanças bilaterais.

Türkay (2014) utiliza dados anuais de 1980 a 2012 e modelos VEC para analisar a condição de Marshall-Lerner na balança comercial da Turquia com o resto do mundo. Os resultados indicam a validade dessa relação.

$\mathrm{O}$ artigo de Bahmani-Oskooee e Fariditavana (2015) procura investigar a ocorrência da curva J para Japão, Canadá, EUA e China, com dados trimestrais de 1973 a 2014. Além de utilizar o modelo ARDL convencional, o trabalho inova ao empregar também o modelo ARDL não linear (NARDL). Através do modelo ARDL, os autores observam evidência positiva da curva J para os Estados Unidos; já com o modelo NARDL, para os Estados Unidos e China.

Através das mesmas técnicas, o artigo de Bahmani-Oskooee e Fariditavana (2016) analisa o fenômeno da curva J nas seis balanças bilaterais dos Estados Unidos, com dados trimestrais de 1973 a 2014. Empregando o modelo ARDL, os autores observam a ocorrência da curva J para três 
casos. Com o modelo NARDL, tal fenômeno ocorre em cinco casos. As conclusões de Nusair (2017) são mais drásticas; ou seja, testando a ocorrência da curva J para 16 países do Leste Europeu, com dados trimestrais de 1994 a 2015 e as mesmas metodologias, não se encontra a curva J para nenhum dos casos através do modelo ARDL; enquanto, utilizando o arcabouço NARDL, há evidência positiva da curva J para 12 países.

\subsection{Evidências para o Brasil}

A literatura que investiga a ocorrência e a regularidade empírica das previsões teóricas mencionadas na seção anterior evoluiu nos últimos anos para o Brasil e diversos autores apresentaram suas contribuições. Um dos primeiros esforços nessa direção pode ser encontrado em Bahmani-Oskoee e Malixi (1992), que procuram investigar a curva J e a validade da condição de Marshall-Lerner para 13 países, entre eles o Brasil, com dados trimestrais do início de 1973 ao final de 1985. Os autores encontram evidências favoráveis de ambos os fenômenos para o Brasil.

Bahmani-Oskoee e Alse (1994) ampliam a abordagem do trabalho anterior para 19 países desenvolvidos e 22 países em desenvolvimento (Brasil incluso) através de dados trimestrais, entre 1971 e 1990, e vetores de correção de erros (VEC). Os resultados confirmam a validade da condição de Marshall-Lerner, mas não atestam a ocorrência do fenômeno da curva J para o Brasil.

Gomes e Paz (2005) utilizam dados mensais de janeiro de 1990 a dezembro de 1998 e o procedimento de cointegração multivariado de Johansen. Os autores confirmam a ocorrência de ambos os fenômenos.

O trabalho de Moura e Da Silva (2005) também investiga a validade da condição de Marshall-Lerner e a ocorrência do fenômeno da curva J para a balança comercial brasileira, desta vez com dados mensais entre janeiro de 1990 a dezembro de 2003 e vetores de correção de erros com mudança de regime (MS-VECM). O autor verifica que, após uma depreciação cambial, a balança comercial tende a se ajustar rapidamente, apresentando um overshooting em vez de uma deterioração inicial, constituindo assim uma evidência positiva para a condição de Marshall-Lerner e negativa para a curva J.

Examinando o fenômeno da curva J nas exportações líquidas do Brasil, com dados trimestrais entre 1980 e 2005 e vetores de correção de erros 
(VEC), Lobo (2007) aponta para a não ocorrência desse fenômeno na balança comercial brasileira.

Analisando as relações de curto e longo prazos entre a balança comercial e as depreciações cambiais sob uma ótica bilateral entre Brasil e os Estados Unidos, Mercosul, União Europeia e resto do mundo, Vasconcelos (2010) faz uso de dados trimestrais entre 1990 e 2009 e de modelos VEC e ARDL. Os resultados não conseguem sustentar a ocorrência do fenômeno da curva J em nenhum dos casos considerados, todavia, os efeitos de longo prazo apontam para a validade da condição de Marshall-Lerner em todas as análises bilaterais.

Sonaglio, Scalco e Campos (2010) realizam uma investigação empírica da ocorrência e regularidade empírica da curva J e da condição de Marshall-Lerner para 21 setores da balança de manufaturados no comércio bilateral entre Brasil e Estados Unidos entre 1994 e 2007 com modelos VEC. Os autores encontram evidências da ocorrência do fenômeno da curva J apenas para os setores de indústrias diversas e óleos vegetais. A condição de Marshall-Lerner, por sua vez, se mostrou presente em seis setores, quais sejam, borracha, calçados, equipamentos eletrônicos, madeira e mobiliário, peças e outros veículos e artigos de vestuário.

Mortatti, Miranda e Bacchi (2011), destacando a importância desempenhada pela China no comércio exterior brasileiro, investigam as variáveis determinantes nas exportações do Brasil para a China nas equações de exportação de commodities agrícolas, minerais e na de exportação de produtos industriais, utilizando dados mensais entre janeiro de 1995 e dezembro de 2008 e modelos VEC. Os autores mostram que tanto a renda brasileira como a chinesa são importantes para o comércio entre esses países em todos os casos considerados. A taxa de câmbio, por outro lado, mostrou-se pouco relevante para a exportação de commodities, mas fortemente determinante para os produtos industrializados. Os autores também verificam a ocorrência do fenômeno da curva J no comércio bilateral Brasil-China para as commodities agrícolas e para os produtos industrializados.

Investigando os efeitos de curto e longo prazos das desvalorizações cambiais sobre o saldo da balança comercial agropecuária do Brasil/resto do mundo com uso de dados mensais entre julho de 1994 a dezembro de 1997 e modelos VEC, Scalco, Carvalho e Campos (2012) rejeitam a ocorrência do fenômeno da curva J e confirmam a validade da condição de Marshall-Lerner. 
Mais recentemente, Ramos Filho e Ferreira (2016) analisam a ocorrência da curva J em 19 setores industriais da balança comercial entre o Brasil e o resto do mundo, com dados anuais entre 1996 e 2012 e modelos ARDL. Os resultados mostram que nenhum dos setores apresenta evidências para a curva J completa, isto é, curva J e condição de Marshall-Lerner. Todavia, os autores observam a chamada curva J incompleta em cinco dos setores analisados.

Casagrande et al. (2019) analisam o desempenho das exportações brasileiras de produtos básicos e de manufaturados para os blocos de países da Ásia, do Acordo de Livre Comércio da América do Norte (NAFTA), da União Europeia e do Mercosul entre os anos de 1999 e 2013. Os autores observam que o comércio de produtos básicos com esses blocos de países se mostra bastante sensível à renda externa. Já as exportações de manufaturados se mostram mais sensíveis às mudanças na taxa de câmbio do que as exportações de produtos básicos.

Considerando aspectos regionais, pode-se afirmar que a literatura nacional pouco avançou. Um primeiro esforço pode ser observado em Moraes et al. (2015), que investigam a ocorrência da curva J no Estado do Rio Grande do Sul - nas balanças comerciais agregadas, dos bens básicos e dos bens industrializados - com dados mensais de janeiro de 1999 a maio de 2014, através do arcabouço VEC e funções de impulso-resposta. Os autores confirmam somente a ocorrência da curva J incompleta nos três casos, uma vez que, apesar de observarem um déficit de curto prazo, o superávit de longo prazo não se mostrou suficiente para repor integralmente a deterioração cambial nas balanças analisadas.

Através das mesmas técnicas, Arruda e Martins (2016) procuram investigar a validade da condição de Marshall-Lerner e também da curva J para o Estado do Ceará - nas balanças comerciais agregadas, dos bens básicos e dos industrializados - com dados mensais de janeiro de 2000 a julho de 2013. O artigo observa a validade de ambos os fenômenos para a balança agregada e dos bens industrializados, e a validade somente da condição de Marshall-Lerner para os bens básicos. Em estudo semelhante para a região Sul do Brasil, Arruda, Castelar e Martins (2019) observam a validade da condição de Marshall-Lerner e a não ocorrência da curva J.

Em suma, apesar das contribuições mencionadas anteriormente, percebe-se a existência de poucos estudos que apresentem evidências sobre a ocorrência do fenômeno da curva J e a validade da condição de Marshall-Lerner em um contexto regional. 


\section{Aspectos metodológicos}

\subsection{Banco de dados}

Para investigar os impactos de curto e de longo prazo da taxa de câmbio real sobre as exportações líquidas dos estados brasileiros, far-se-á uso do arcabouço de dados em painel contendo informações de 10 estados (Bahia, Pernambuco, Ceará, São Paulo, Rio de Janeiro, Minas Gerais, Espírito Santo, Rio Grande do Sul, Paraná e Santa Catarina) entre janeiro de 1999 e dezembro de 2015. A investigação dos impactos de curto prazo justifica o emprego de dados na frequência mensal. Vale destacar que apenas os 10 estados supracitados continham informações disponíveis para as variáveis empregadas.

Como é padrão nessa literatura, o indicador de exportações líquidas é dado pela razão entre as exportações e as importações (Bahmani-Oskoee; Kantiapong, 2001; Moura; Da Silva, 2005; Arruda; Castelar; Martins, 2019). Essa variável será construída a partir de dados de exportações e importações por fator agregado, adquiridos junto à Secretaria de Comércio Exterior do Ministério do Desenvolvimento, Indústria e Comércio Exterior (SECEX/MDIC). Esse indicador será empregado, considerando os valores totais e o saldo para os básicos e industrializados.

Diversas são as vantagens do emprego dessa variável: a) ela permanece constante, independentemente da unidade de medida considerada (Bahmani-Oskoee; Alse, 1994); b) representa as exportações líquidas em termos reais ou nominais (Bahmani-Oskoee; Kantiapong, 2001); c) após o seu registro é possível extrair sua taxa de crescimento a partir da primeira diferença, se ela estiver em logaritmo (Brada; Kutan; Zhou, 1997). O Quadro 1 apresenta uma síntese das variáveis utilizadas.

Em virtude da indisponibilidade de dados sobre PIB mensal para os estados brasileiros, utilizar-se-á como proxy para essa variável o Índice de Produção Industrial (IPI) de cada Estado.7 O IPI estadual é calculado e disponibilizado pelo Instituto Brasileiro de Geografia e Estatística (IBGE). Vale destacar que esse indicador também foi empregado em estudos como os de Arruda e Ferreira (2014) e Arruda e Martins (2016).

A proxy para a renda do resto do mundo, ou demanda externa, empregada 
neste estudo será o valor das importações mundiais divulgados na International Financial Statistics (IFS) publicada pelo Fundo Monetário Internacional (FMI). Os valores foram deflacionados pelo Índice de Preços por Atacado dos Estados Unidos (IPA), que também se encontra disponível nas IFS-FMI.

Quadro 1 Descrição das variáveis utilizadas

\begin{tabular}{|c|c|c|c|}
\hline Variável & Proxy utilizada & Período da série & Fonte dos dados \\
\hline Câmbio real ${ }_{\text {it* }^{*}}$ & $\begin{array}{l}\text { Logaritmo natural da taxa de } \\
\text { câmbio real efetiva }\end{array}$ & 01/1999 - 12/2015 & BCB-SGS \\
\hline Renda externa $\mathrm{it*}$ & $\begin{array}{l}\text { Logaritmo natural das importa- } \\
\text { ções Mundiais }\end{array}$ & 01/1999 - 12/2015 & IFS-FMI \\
\hline Renda doméstica ${ }_{i t}$ & $\begin{array}{l}\text { Logaritmo natural do índice de } \\
\text { produção industrial do estado i, } \\
\text { no mês t }\end{array}$ & 01/1999 - 12/2015 & IBGE \\
\hline $\begin{array}{l}\text { Exportações líquidas } \\
\text { (Totais) }{ }_{\text {it }}\end{array}$ & $\begin{array}{l}\text { Logaritmo natural da razão } \\
\text { (exportações/importações) - } \\
\text { totais - do estado i, no mês t }\end{array}$ & $01 / 1999-12 / 2015$ & MDIC/SECEX \\
\hline $\begin{array}{l}\text { Exportações líquidas } \\
(\text { Básicos })_{\text {it }}\end{array}$ & $\begin{array}{l}\text { Logaritmo natural da razão } \\
\text { (exportações/importações) - } \\
\text { setor Básicos - do estado i, no } \\
\text { mês t }\end{array}$ & 01/1999 - 12/2015 & MDIC/SECEX \\
\hline 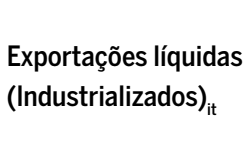 & $\begin{array}{l}\text { Logaritmo natural da razão } \\
\text { (exportações/importações) - } \\
\text { setor Industrializados - do } \\
\text { estado i, no mês t }\end{array}$ & 01/1999-12/2015 & MDIC/SECEX \\
\hline
\end{tabular}

Fonte: Elaboração própria.

* As variáveis de renda externa e de taxa de câmbio real serão as mesmas para todas as unidades do painel.

A medida de câmbio utilizada nesta pesquisa é a taxa de câmbio efetiva real, que é calculada a partir de uma média geométrica ponderada dos maiores parceiros comerciais de uma economia e é empregada como uma medida de competitividade das exportações de um país. Optou-se pela taxa de câmbio efetiva real, considerando o Índice de Preços por Atacado - Disponibilidade Interna (IPA-DI), disponibilizada no Sistema Gerador de Séries Temporais do Banco Central do Brasil (BCB-SGS) -, uma vez que este considera apenas bens transacionáveis.

De modo a verificar a representatividade dos 10 estados considerados neste estudo, no que diz respeito ao comercio internacional, o Gráfico 1 
apresenta a evolução da participação percentual da corrente de comércio ${ }^{8}$ desses estados nas relações comerciais do Brasil. Inicialmente, observa-se que os totais e os industrializados apresentaram participações acima de $80 \%$ da corrente de comércio do país em todo o período considerado, tendo importâncias médias de $86 \%$ e $83 \%$, respectivamente. Considerando a evolução dos básicos, observa-se maior dinâmica, saindo de uma fração de $56 \%$, em 1999, para 86\%, em 2015, apresentando participação média de $67 \%$; ou seja, os 10 estados considerados neste estudo se mostram bastante representativos nas relações comerciais do Brasil.

\section{Gráfico 1 Participação da corrente de comércio dos estados utilizados no comércio do}

\section{Brasil (\%)}

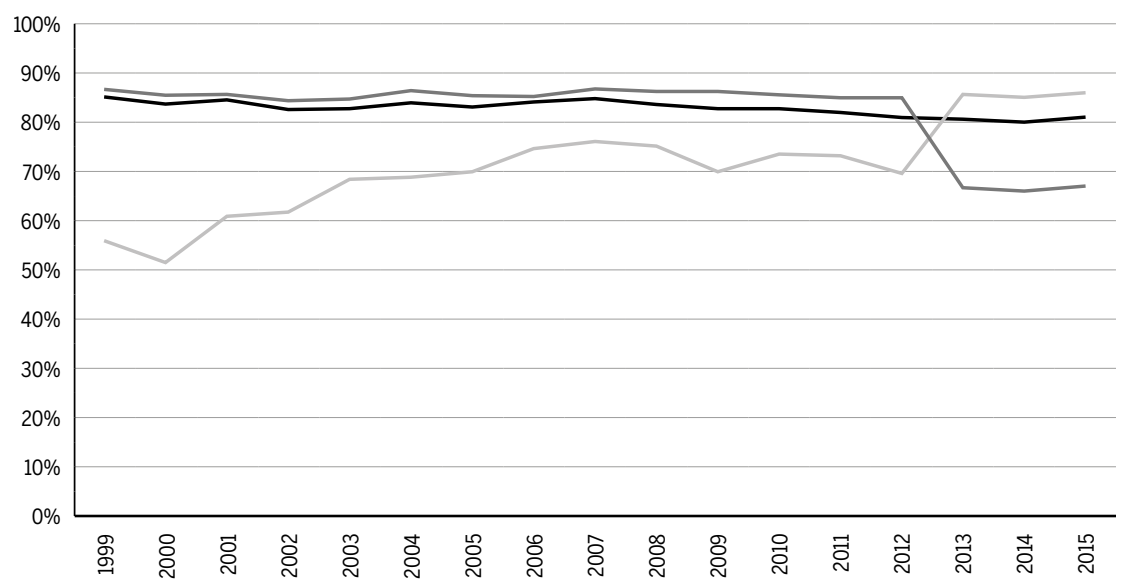

— Participação nos Totais

— Participação nos Básicos

Participação nos Industrializados

Fonte: Elaboração própria a partir dos dados da SECEX/MDIC.

\subsection{Estratégia econométrica}

Em anos recentes, uma linha de pesquisa em séries temporais que tem despertado bastante interesse é a estimação de modelos para dados em painel não estacionários, especialmente através da análise de cointegra-

8 Corrente de comércio é definida como a soma dos valores das exportações e importações. 
ção nesse arcabouço e da mitigação de problemas associados à regressão espúria em painel.

Nesse contexto, a disponibilidade cada vez maior de informações, tanto temporais como cross-section, tem estimulado o desenvolvimento de técnicas de estimação para as relações de longo prazo em painéis cointegrados. Entre elas, destacam-se o Pooled Ordinary Least Squares (POLS), que estima as relações de longo prazo, sem considerar a heterogeneidade não observada; o Panel Fully Modified Ordinary Least Squares (PFMOLS), proposto por Pedroni (1997) e Phillips e Moon (1999), que considera a presença de heterogeneidade no painel e, por fim, o Panel Dynamic Ordinary Least Squares (PDOLS), que é uma extensão do DOLS, proposto por Stock e Watson (1993) para modelos de séries temporais, empregada em dados em painel por Kao e Chiang (2000).

Kao e Chiang (2000) comparam a performance dos estimadores POLS, PFMOLS e PDOLS. Os autores mostram um intenso viés nos estimadores POLS e PFMOLS, com o PDOLS apresentando o melhor desempenho. Além disso, os autores mostram que o estimador PDOLS se mostrou consistente e com estatísticas t convergentes em distribuição. Stock e Watson (1993) argumentam que o PDOLS é uma técnica para se obter estimadores eficientes para os vetores de cointegração que incluam componentes determinísticos e acomodem indistintamente variáveis de alta ordem de integração, de ordens de integração distintas, desde que sejam cointegradas. Ainda segundo esses autores, a presença de leads e lags de diferentes variáveis na equação de estimação, a qual possui um vetor cointegrante, elimina o viés de simultaneidade, bem como o viés de pequenas amostras.

Nesse sentido, para a análise das repercussões de uma depreciação cambial real sobre as exportações líquidas dos estados brasileiros, utiliza-se a definição de balança comercial/exportações líquidas comumente empregada em estudos dessa natureza, ${ }^{9}$ qual seja, a razão entre os valores das exportações e importações $\left(X_{i t} / M_{i t}\right)$ para os setores considerados como função da renda doméstica $\left(Y_{i t}\right)$, da renda externa $\left(Y^{*}{ }_{i t}\right)$, da taxa de cambio efetiva real $\left(T X C E R_{i t}\right)$ e de seus lags e leads; ou seja, a representação PDOLS, nos moldes de Kao e Chiang (2000), para esse modelo será:

9 Ver Moura e Da Silva (2005), Sonaglio, Scalco, Campos (2010), Vasconcelos (2010) e Scalco, Carvalho, Campos (2012). 


$$
\begin{aligned}
& \ln \left(\frac{X_{i t}}{M_{i t}}\right)=\alpha_{i}+\beta_{1} \ln \left(T X C E R_{i t}\right)+\beta_{2} \ln \left(Y_{i t}\right)+\beta_{3} \ln \left(Y_{i t}^{*}\right)+ \\
& +\sum_{s=-p_{i}}^{p_{i}} \varphi_{i} \Delta \ln \left(T X C E R_{i t+s}\right)+\sum_{s=-m}^{m_{i}} \theta_{i} \Delta \ln \left(Y_{i t+s}\right)+ \\
& +\sum_{s=-n_{i}}^{n_{i}} \psi_{i} \Delta \ln \left(Y_{i t+s}^{*}\right)+\varepsilon_{i t}
\end{aligned}
$$

onde: $i=1,2,3, \ldots, 10 ; t=1999.1,1999.2, \ldots, 2015.12 ; \operatorname{In}\left(X_{i t} / M_{i t}\right)=$ logaritmo natural da razão exportações/importações, ou exportações líquidas, do estado $i$, no tempo $t$ (esse indicador será utilizado, considerando os valores totais, dos básicos e dos industrializados; perfazendo um total de três modelos); $\operatorname{In}\left(Y_{i t}\right)=$ logaritmo natural da proxy de renda doméstica do estado $i$, no tempo $t ; \operatorname{In}\left(T X C E R_{i t}\right)=$ logaritmo natural da taxa de câmbio efetiva real (câmbio real) para o estado $i$, no tempo $t ; \operatorname{In}\left(Y_{i t}^{*}\right)=$ logaritmo natural da renda real do resto do mundo (renda externa) para o estado $i$, no tempo $t ; \beta_{1}, \beta_{2}, \beta_{3}=$ parâmetros a serem estimados; $\alpha_{i}$ incorpora os efeitos fixos do painel; $p_{i}, m_{i}$ e $n_{i}$ são os leads; $-p_{i},-m_{i}$ e $-n_{i}$ são os lags; $\varepsilon_{i t}=$ termo de erro.

Portanto, a estratégia econométrica inicial consiste na análise de cointegração em painel entre as variáveis a partir das quatro estatísticas propostas por Westerlund (2007) que apresentam melhor desempenho frente a outros testes usuais, como os de Pedroni (1999; 2004) e os de Cheng, Wei e Hou (2008). O teste de Westerlund (2007) tem como hipótese nula a ausência de cointegração entre as variáveis. Além disso, o teste permite o controle da dependência e da heterogeneidade entre as unidades de corte transversal do painel via métodos de bootstrap. Em caso de cointegração, aplica-se o método PDOLS para estimar a relação de longo prazo entre as exportações líquidas e as demais variáveis propostas, como descrito anteriormente.

Para analisar os efeitos de curto prazo, utilizar-se-á o arcabouço dos modelos Panel Vector Autoregression (PVAR). Todavia, inicialmente analisar-se-á a ordem de integração das séries utilizadas através do teste de Levin, Lin e Chu (2002) - LLC, que temcomo hipótese nula a presença de uma raiz unitária comum a todas as unidades no painel, e de Im, Pesaran e Shin (2003) - IPS, que testa a presença de raiz unitária individual nos crosssection. As variáveis que se mostrarem estacionárias entrarão no modelo em nível, ao passo que aquelas que forem I(1) serão incluídas nos modelos em primeiras diferenças. Em seguida, proceder-se-á à estimação de um PVAR para analisar a ocorrência do fenômeno da curva J. Essas evidências serão verificadas a partir das Funções de Impulso Resposta (FIR), extraídas 
de um PVAR, com a estrutura originalmente empregada em Binder, Hsiao e Pesaran (2005):

$$
Z_{i, t}=\left(I_{m}-\Phi\right) \mu_{i}+\Phi Z_{i, t-1}+\varepsilon_{i, t}
$$

em que $i=1,2,3, \ldots, 10 ; t=1999.1,1999.2, \ldots, 2015.12 ; Z_{i, t}$ é um vetor ntx1 de variáveis endógenas contendo as exportações líquidas, as proxies de renda doméstica e externa e a taxa de cambio efetiva real; $\Phi$ é uma matriz mxm de parâmetros a serem estimados; $\mu_{i}$ é um vetor mx1 que incorpora os efeitos individuais; $\varepsilon_{i, t}$ é o termo de erro, e $I_{m}$ é uma matriz identidade de dimensão mxm. Vale destacar que serão estimados três modelos, quais sejam, para as exportações líquidas totais, dos básicos e dos industrializados.

Como se utiliza um modelo com dados em painel, é importante levar em consideração a heterogeneidade não observada dos estados. Por isso, utilizar-se-á o estimador de efeitos fixos, por Mínimos Quadrados com Variáveis Dummies (LSDV), onde $\mu_{i}$ incorpora o efeito específico de cada unidade cross-section. Vale destacar que Nickell (1981) e Hahn e Kuersteiner (2002) mostram que esse estimador se mostra consistente para painéis com dimensão temporal grande, que é o caso deste estudo. Após a estimação dos modelos, são analisadas as FIRs para identificar a ocorrência do fenômeno da curva J. Os intervalos de confiança para as FIRs serão obtidos através do procedimento de bootstrap proposto por Hall (1992).

Em suma, a estratégia econométrica empregada neste estudo pode ser assim resumida: após uma criteriosa análise da existência de cointegração entre as variáveis dos modelos constantes na equação (5), através do teste de cointegração de Westerlund (2007), proceder-se-á à estimação de um PDOLS para cada caso considerado; ou seja, para as exportações líquidas dos totais, dos básicos e, por fim, dos industrializados. Portanto, serão estimados três modelos PDOLS para analisar a validade da condição de Marshall-Lerner. Em seguida, são analisados os impactos da taxa de câmbio real sobre as exportações líquidas em curto prazo, através das FIRs extraídas de um PVAR.

\section{Análise e discussão dos resultados}

Como descrito na seção anterior, para examinar os aspectos relacionados à validade/regularidade da condição de Marshall-Lerner e a ocorrência do 
fenômeno da curva J, inicialmente procedeu-se à investigação sobre a existência de uma relação de longo prazo, ou de cointegração, entre as variáveis utilizadas, via teste de Westerlund (2007).

O teste de cointegração de Westerlund (2007) faz uso de quatro estatísticas, sendo duas na versão Group-Means (Ga e $\mathrm{Gt}$ ) e duas na versão Panel-Tests ( $\mathrm{Pa}$ e $\mathrm{Pt}$ ). As primeiras verificam a cointegração em pelo menos uma unidade do painel, enquanto as demais a verificam para o painel como um todo. Os resultados estão sintetizados na Tabela 1 e mostram que, em todos os modelos e para as quatro estatísticas de teste, rejeita-se a hipótese nula de ausência de cointegração, tanto para grupos de unidades cross-section como para o painel completo e, portanto, atestam uma relação de longo prazo entre essas variáveis. As subseções seguintes discorrem sobre os resultados para as relações de longo prazo e de curto prazo, respectivamente.

Tabela 1 Resultados dos testes de cointegração de Westerlund (2007)

\begin{tabular}{lrrrr}
\hline $\begin{array}{l}\text { Estatística/ } \\
\text { Modelo }\end{array}$ & $\begin{array}{r}\text { Exportações líquidas } \\
\text { Totais }\end{array}$ & $\begin{array}{r}\text { Exportações líquidas } \\
\text { (Básicos) }\end{array}$ & $\begin{array}{r}\text { Exportações líquidas } \\
\text { (Industrializados) }\end{array}$ \\
\hline \multirow{2}{*}{$G_{\mathrm{t}}$} & $-5,26^{*}$ & $-5,45^{*}$ & $-4,58^{*}$ \\
\hline \multirow{2}{*}{$\mathrm{G}_{\mathrm{a}}$} & $(-3,47)$ & $(-3,65)$ & $(-2,81)$ \\
\hline \multirow{2}{*}{$\mathrm{P}_{\mathrm{t}}$} & $-57,23^{*}$ & $-55,26^{*}$ & $-44,85^{*}$ \\
& $(-7,91)$ & $(-7,59)$ & $(-5,93)$ \\
\hline \multirow{2}{*}{$\mathrm{P}_{\mathrm{a}}$} & $-5,26^{*}$ & $-5,45^{*}$ & $-4,58^{*}$ \\
& $(-3,03)$ & $(-3,15)$ & $(-2,49)$ \\
\hline
\end{tabular}

Fonte: Elaboração própria.

Notas: a) Estatística Z em parênteses; b) *Significante a 1\%. c) Testes realizados com até seis lags e leads.

\subsection{Resultados para a condição de Marshall-Lerner}

Após a identificação da cointegração entre as variáveis, procedeu-se à estimação das relações de longo prazo utilizando PDOLS para as exportações líquidas dos totais, dos básicos e dos industrializados, respectivamente. A tabela 2 sintetiza os resultados. Vale destacar que o critério de Schwarz indicou seis como o número ótimo de lags e lead em todos os 
modelos estimados. Portanto, serão estimados três modelos PDOLS $(6,6)$. Inicialmente, observa-se que a estatística de Wald atesta a significância global da relação entre essas variáveis, mesmo no nível de significância de $1 \%$. Vale lembrar que a condição de Marshall-Lerner será satisfeita se o coeficiente estimado do efeito da taxa de câmbio real for positivo e estatisticamente significante.

Tabela 2 Resultados PDOLS para as relações de longo prazo

\begin{tabular}{lrr|r|r|r}
\hline $\begin{array}{l}\text { Estatística/ } \\
\text { Modelo }\end{array}$ & $\begin{array}{r}\text { Taxa de } \\
\text { câmbio real }\end{array}$ & $\begin{array}{r}\text { Renda } \\
\text { doméstica }\end{array}$ & $\begin{array}{r}\text { Renda } \\
\text { externa }\end{array}$ & Teste \\
\hline Exportações líquidas totais & 1,01 & $-0,20$ & 0,34 & 99,52 \\
& {$[9,95]$} & {$[-2,67]$} & {$[3,36]$} & $(0,00)$ \\
\hline Exportações líquidas & 1,06 & $-0,25$ & 0,99 & 70,90 \\
(Básicos) & {$[6,94]$} & {$[-2,30]$} & {$[6,56]$} & $(0,00)$ \\
\hline Exportações líquidas & 1,57 & $-0,19$ & 0,28 & 74,24 \\
(Industrializados) & {$[14,68]$} & {$[-2,58]$} & {$[2,62]$} & $(0,00)$ \\
\hline
\end{tabular}

Fonte: Elaboração própria.

Notas: a) Os três modelos foram estimados com seis lags e seis leads; ou seja, PDOLS (6,6); b) P-Valor entre parêntesis; c) Estatística Z entre colchetes.

Em termos gerais, as evidências encontradas apontam para a validade da condição de Marshall-Lerner em todos os modelos considerados. Ou seja, os resultados indicam que o efeito de longo prazo de uma depreciação cambial é positivo e estatisticamente robusto sobre as exportações líquidas dos estados brasileiros. Portanto, esses modelos regionais parecem reproduzir as principais evidências encontradas para a economia brasileira, sobre a condição de Marshall-Lerner (Moura; Da Silva, 2005; Vasconcelos, 2010; Scalco; Carvalho; Campos, 2012). Vale destacar que Arruda e Martins (2016) e Arruda, Castelar e Martins (2019) também observam a validade dessa relação para as exportações líquidas do Estado do Ceará e da região Sul do Brasil, respectivamente.

Além disso, os resultados também indicam que esses efeitos se mostram elásticos em todos os modelos considerados; ou seja, incrementos de $10 \%$ na taxa de câmbio real aumentam em $10,1 \%, 10,6 \%$ e $15,7 \%$, respectivamente, as exportações líquidas totais, de básicos e de industrializados. Esse resultado reflete a maior participação dos produtos industrializados nesses estados que, como mostra o Gráfico 1 referido anteriormente, apre- 
sentaram participação média de $83 \%$ do total das relações comerciais de industrializados do país. Os resultados mais discretos para os básicos podem ser justificados pelas ausências de estados como Maranhão, Piauí e Tocantins (que com o estado da Bahia formam a região da MATOPIBA, que tem se destacado na produção agrícola), Goiás e Mato Grosso do Sul (que se destacam na pecuária). Ainda assim, os resultados seguiram a linha dos observados por Mortatti, Miranda, Bacchi (2011) e Scalco, Carvalho e Campos (2012) para esse setor.

Do ponto de vista teórico, esses resultados parecem fornecer indícios, sob a ótica da absorção, de que o efeito substituição parece sobrepujar o efeito renda em longo prazo, dada a ocorrência de superávit em todos os dos casos analisados.

Dessa forma, esses resultados sinalizam a importância da autoridade monetária na condução da política cambial, de modo a manter a taxa de câmbio real em patamares competitivos, a fim de aumentar a inserção de produtos exportados por esses estados no mercado internacional, uma vez que em todos os casos considerados as exportações líquidas apresentaram respostas elásticas à taxa de câmbio real. Além disso, Palma (2007) observa que a política monetária se mostra sensível a choques na taxa de câmbio e que negligenciar essa relação pode produzir distorção na condução desse instrumento de política econômica.

A renda externa também se mostrou estatisticamente significante em todos os modelos considerados e com o sinal esperado; ou seja, um aumento na renda externa pode se reproduzir como um incremento na demanda por exportações domésticas o que, ceteris paribus, melhora o saldo comercial. Vale destacar que esse impacto se mostrou superior para básicos; ou seja, as exportações líquidas de bens básicos aumentam em 9,9\%, em resposta a incrementos de $10 \%$ na demanda externa. Em condições semelhantes, no setor de industrializados, o aumento seria de 2,8\%. Além de confirmar a previsão teórica, esse resultado também reflete a importante participação dos bens básicos, especialmente commodities agrícolas, nas exportações dos estados brasileiros, o que torna esse setor mais sensível às oscilações da demanda externa.

Portanto, diante do exposto, sugere-se uma política de maior abertura comercial, que pode ser praticada tanto em nível estadual quanto nacional, uma vez que o Brasil ainda apresenta taxas de abertura comercial bastante discretas. Os dados da SECEX/MDIC mostram que o país apresentou uma 
taxa de abertura média (medida pela soma das exportações com as importações, dividida pelo PIB) de $20 \%$ no período analisado; ou seja, ainda há espaço para ampliar essa participação de modo a se beneficiar de uma maior demanda externa.

Por fim, a renda doméstica apresentou impacto negativo e estatisticamente significante sobre as exportações líquidas, uma vez que um incremento nesse indicador aponta para um aumento na demanda por importações o que, ceteris paribus, produz uma deterioração no saldo comercial. Especificamente, aumentos de $10 \%$ na renda doméstica se refletiriam em reduções de 2,5\% e 1,9\% no saldo comercial de básicos e industrializados, respectivamente. Entretanto, a magnitude dessas elasticidades deve ser analisada com cautela, dado que a proxy empregada ${ }^{10}$ incorpora apenas os incrementos na atividade industrial, não refletindo, portanto, a integralidade da renda doméstica.

\subsection{Resultados para a curva J}

Uma vez que não se rejeita a validade da condição de Marshall-Lerner em todos os níveis da balança comercial considerados; ou seja, o efeito de longo prazo de uma depreciação cambial sobre as exportações líquidas dos estados brasileiros é positivo. Resta agora testar a ocorrência do fenômeno da curva J.

Nesse sentido, inicialmente analisou-se a ordem de integração das séries através dos testes de raiz unitária de Levin, Lin e Chu (2002) e Im, Pesaran e Shin (2003), cujos resultados se encontram na Tabela 3. Ambos os testes apontam que todas as varáveis se mostram estacionárias em nível e, portanto, são I(0). Assim, todas as variáveis serão incluídas em nível nos modelos aqui empregados.

Em seguida, procedeu-se à análise das FIRs extraídas de modelos PVAR, que investigam qual a trajetória estimada (resposta) da balança comercial, dado um choque (impulso) na taxa de câmbio real, nesse caso, uma desvalorização cambial. A análise foi realizada na seguinte ordem: inicialmente averiguaram-se tais efeitos para as exportações líquidas totais, seguidas das investigações para os setores de básicos e industrializados, respecti-

10 Essa proxy tem sido utilizada em virtude da ausência de medidas de renda doméstica na frequência mensal para os estados brasileiros (Arruda; Ferreira, 2014; Arruda; Martins, 2016). 
vamente. Vale destacar que, seguindo o critério de informação de Schwarz, todos os modelos foram estimados com dois lags; ou seja, PVAR (2). As tabelas A1 a A3, em Apêndice, apresentam os modelos estimados.

Tabela 3 Resultados dos testes de raiz unitária

\begin{tabular}{|c|c|c|c|c|}
\hline \multirow[b]{2}{*}{ Variável } & & \multicolumn{3}{|r|}{ Teste } \\
\hline & & $\begin{array}{r}\text { Levin, Lin e } \\
\text { Chu }\end{array}$ & $\begin{array}{r}\text { Im, Pesaran e } \\
\text { Shin }\end{array}$ & Resultado \\
\hline \multirow{2}{*}{ Taxa de câmbio real ${ }_{\text {it }}$} & Nível & $\begin{array}{l}-3,91^{*} \\
(0,00)\end{array}$ & $\begin{array}{r}-2,36^{*} \\
(0,00)\end{array}$ & $\mathrm{I}(0)$ \\
\hline & $\begin{array}{l}\text { Primeira } \\
\text { diferença }\end{array}$ & $\begin{array}{r}-30,08^{*} \\
(0,00)\end{array}$ & $\begin{array}{r}-30,87^{*} \\
(0,00)\end{array}$ & $\mathrm{I}(0)$ \\
\hline \multirow{2}{*}{ Renda externa ${ }_{i t}$} & Nível & $\begin{array}{l}-4,70^{*} \\
(0,00)\end{array}$ & $\begin{array}{r}-3,93^{*} \\
(0,00)\end{array}$ & $\mathrm{I}(0)$ \\
\hline & $\begin{array}{l}\text { Primeira } \\
\text { diferença }\end{array}$ & $\begin{array}{l}-9,42^{*} \\
(0,00)\end{array}$ & $\begin{array}{r}-22,66^{*} \\
(0,00)\end{array}$ & $\mathrm{I}(0)$ \\
\hline \multirow{2}{*}{ Renda doméstica ${ }_{\text {it }}$} & Nível & $\begin{array}{r}-4,29 * \\
(0,00) \\
\end{array}$ & $\begin{array}{r}-8,54^{*} \\
(0,00) \\
\end{array}$ & $\mathrm{I}(0)$ \\
\hline & $\begin{array}{l}\text { Primeira } \\
\text { diferença }\end{array}$ & $\begin{array}{r}-6,84^{*} \\
(0,00)\end{array}$ & $\begin{array}{r}-23,36^{*} \\
(0,00)\end{array}$ & $\mathrm{I}(0)$ \\
\hline \multirow{2}{*}{$\begin{array}{l}\text { Exportações líquidas } \\
\text { (Totais) }_{\text {it }}\end{array}$} & Nível & $\begin{array}{r}-1,83^{* *} \\
(0,03)\end{array}$ & $\begin{array}{r}-3,91 \\
(0,00)\end{array}$ & $\mathrm{I}(0)$ \\
\hline & $\begin{array}{l}\text { Primeira } \\
\text { diferença }\end{array}$ & $\begin{array}{r}-24,48^{*} \\
(0,00)\end{array}$ & $\begin{array}{r}-38,01^{*} \\
(0,00)\end{array}$ & $\mathrm{I}(0)$ \\
\hline \multirow{2}{*}{$\begin{array}{l}\text { Exportações líquidas } \\
\left(\text { Básicos) }{ }_{i t}\right.\end{array}$} & Nível & $\begin{array}{r}-10,24^{*} \\
(0,00) \\
\end{array}$ & $\begin{array}{r}-11,59 * \\
(0,00) \\
\end{array}$ & $\mathrm{I}(0)$ \\
\hline & $\begin{array}{l}\text { Primeira } \\
\text { diferença }\end{array}$ & $\begin{array}{r}-21,63^{*} \\
(0,00)\end{array}$ & $\begin{array}{r}-37,15^{*} \\
(0,00)\end{array}$ & $\mathrm{I}(0)$ \\
\hline \multirow{2}{*}{$\begin{array}{l}\text { Exportações líquidas } \\
\text { (Industrializados) })_{\text {it }}\end{array}$} & Nível & $\begin{array}{r}-2,04^{* *} \\
(0,02)\end{array}$ & $\begin{array}{r}-4,04^{*} \\
(0,00)\end{array}$ & $\mathrm{I}(0)$ \\
\hline & $\begin{array}{l}\text { Primeira } \\
\text { diferença }\end{array}$ & $\begin{array}{r}-21,54^{*} \\
(0,00)\end{array}$ & $\begin{array}{r}-40,19 \\
(0,00)\end{array}$ & $\mathrm{I}(0)$ \\
\hline
\end{tabular}

Fonte: elaborado pelos autores a partir dos resultados obtidos.

Nota: Valor p entre parênteses. * Significante ao nível de 1\%. ${ }^{*}$ Significante ao nível de 5\%.

O Gráfico 2 revela que um choque na taxa de câmbio real repercute inicialmente de forma negativa sobre as exportações líquidas totais dos estados brasileiros, recuperando-se após o primeiro mês até tornar-se superavitária 3 meses depois, caracterizando a ocorrência da curva J. 


\section{Gráfico 2 Resposta das exportações líquidas totais a desvalorizações cambiais}

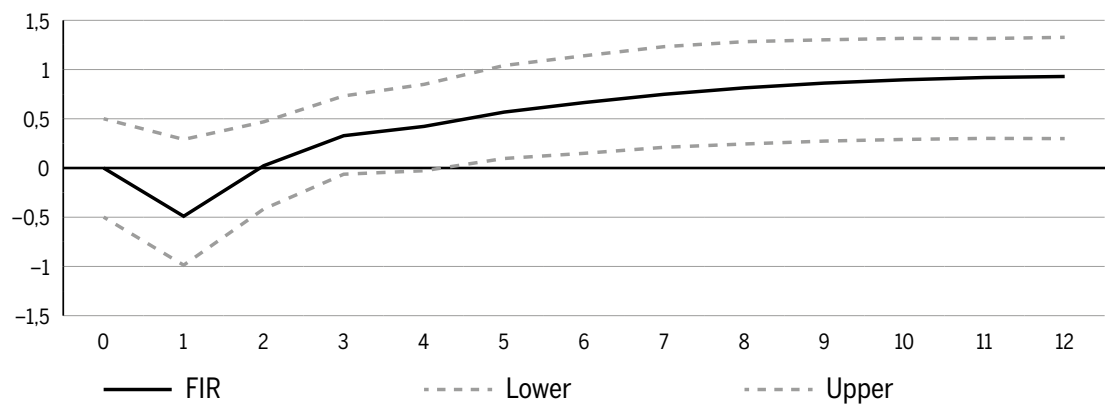

Fonte: Elaboração própria a partir do modelo estimado.

Em seguida, análise semelhante foi realizada considerando apenas os bens básicos. $O$ Gráfico 3 apresenta a respectiva FIR. Os resultados não sustentam a ocorrência do fenômeno da curva J para as exportações líquidas dos básicos, uma vez que seu saldo responde positivamente às depreciações cambiais já no curto prazo.

Gráfico 3 Resposta das exportações líquidas dos básicos a desvalorizações cambiais

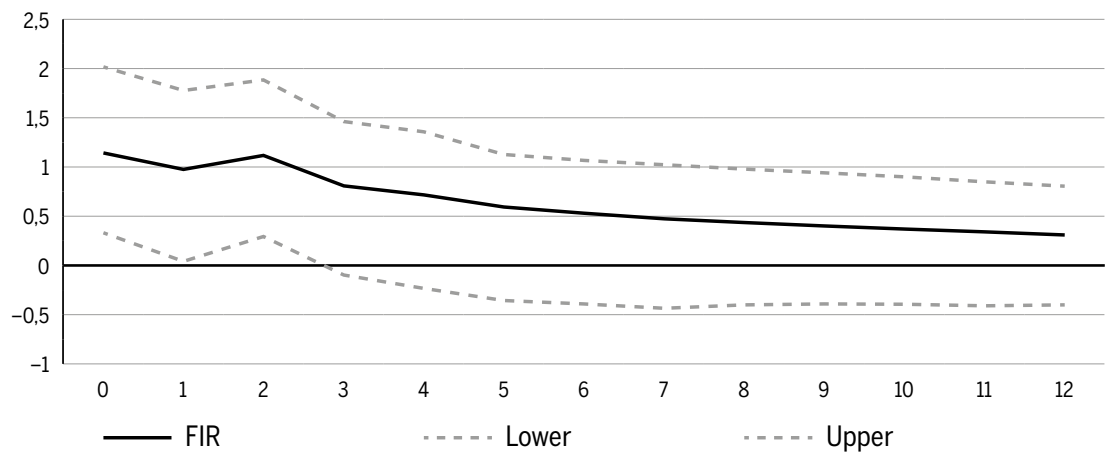

Fonte: Elaboração própria a partir do modelo estimado.

Por fim, analisaram-se as respostas das exportações líquidas de produtos industrializados às depreciações cambiais. Os resultados estão sintetizados no Gráfico 4. Percebe-se que o saldo comercial dos industrializados responde inicialmente de forma negativa, apresentando recuperação a seguir, tornando-se positivo três meses depois; ou seja, evidências de ocorrência da curva J. 


\section{Gráfico 4 Resposta das exportações líquidas dos industrializados a desvalorizações}

\section{cambiais}

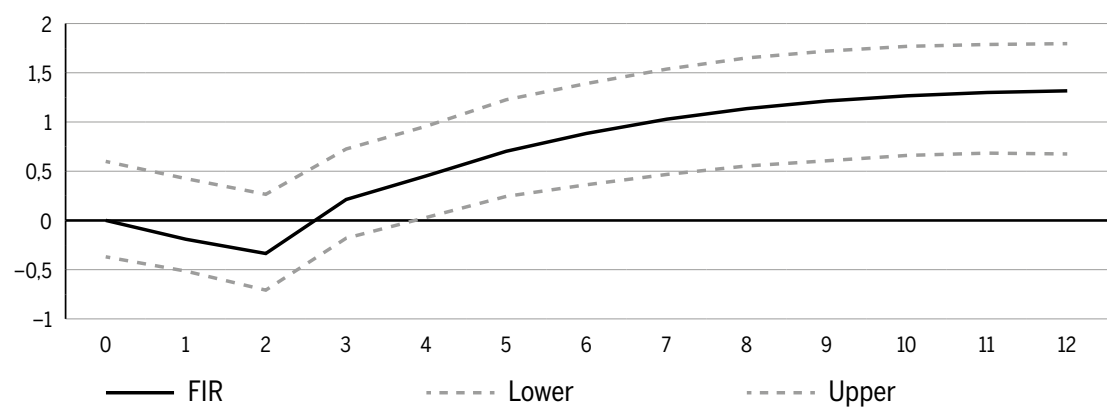

Fonte: Elaboração própria a partir do modelo estimado.

Desse modo, os resultados do presente trabalho corroboram os achados de Bahmani-Oskooee e Malixi (1992), Gomes e Paz (2005) e Vasconcelos (2010) ao indicarem a ocorrência da curva J no comércio Brasil-Resto do Mundo, para os totais e os industrializados, considerando um painel de estados; ou seja, sob a ótica da absorção, o efeito renda parece superar o efeito substituição em curto prazo.

Vale ressaltar que a não ocorrência da curva J na balança dos bens básicos, aqui observada, está em conformidade com os resultados de Scalco, Carvalho e Campos (2012), que diagnosticaram o mesmo para a balança do setor agropecuário, componente de grande importância na balança dos bens básicos. Ressalte-se, ainda, que essas evidências parecem indicar que há um ajuste mais rápido na balança dos bens básicos, de modo que uma desvalorização na taxa de câmbio já resulta em superávit no curto prazo, dado que vários desses bens têm preços cotados em bolsas de valores e mercados futuros.

Em suma, os resultados de longo prazo parecem indicar de modo robusto a validade da condição de Marshall-Lerner para as exportações líquidas dos estados brasileiros, considerando os totais, básicos e industrializados, com os últimos apresentando uma resposta mais elástica. E, ainda, que estas são positivamente influenciadas pela demanda externa e negativamente impactadas pela renda doméstica, refletindo o aumento da demanda por importações. Considerando as evidências de curto prazo, percebe-se a ocorrência do fenômeno da curva J, apenas para os totais e para os industrializados. 


\section{Considerações finais}

O presente trabalho se pautou na análise dos impactos das desvalorizações cambiais sobre as exportações líquidas totais, de básicos e de industrializados para um painel de estados brasileiros a partir da aplicação de modelos PVAR, para testar a ocorrência do fenômeno da curva J, e do PDOLS, para investigar a validade da condição de Marshall-Lerner. As contribuições potenciais da pesquisa estão na aplicação de técnicas ainda não empregadas em estudos dessa natureza e na regionalização do exercício.

O exame das relações de longo prazo permitiu inferir que em todos os modelos considerados a reposta das exportações líquidas dos estados brasileiros a uma depreciação cambial se mostra positiva, validando, portanto, a condição de Marshall-Lerner. Vale destacar que Moura e Da Silva (2005), Vasconcelos (2010) e Scalco, Carvalho e Campos (2012) encontraram evidências semelhantes em dados agregados do Brasil.

A renda doméstica se mostrou estatisticamente robusta e com sinal previsto pela teoria; ou seja, um aumento nesse indicador promove uma deterioração nas exportações líquidas dos estados brasileiros, por aumentar a demanda por importações. As evidências também indicam que, majorando-se a renda externa, o saldo comercial dos estados brasileiros responderá de maneira positiva, uma vez que esse aumento será reproduzido num incremento da demanda por suas exportações.

Por fim, a análise das relações de curto prazo via PVAR apontou para a validade da curva J nas exportações líquidas totais e dos industrializados nos estados do Brasil. No caso dos básicos, não se observou esse fenômeno, resultado que converge para o observado por Scalco, Carvalho e Campos (2012).

Em termos práticos, os achados neste estudo apontam para a importância de políticas que propiciem maior inserção dos estados brasileiros no comércio internacional, a partir de medidas que possam ser conduzidas tanto no âmbito estadual quanto no nacional, dado que, em todos os casos considerados, a demanda externa se mostrou benéfica para o saldo comercial. Além disso, os resultados também reforçam a importância da autoridade monetária na condução da política cambial, de modo a manter esse indicador em níveis competitivos, uma vez que, em todos os modelos analisados, as exportações líquidas se beneficiaram das desvalorizações reais no câmbio. 
Apesar de representar um primeiro esforço nessa literatura, no que tange a exercícios regionais para painéis de estados, o presente estudo pode ser ampliado em duas frentes; quais sejam, estudos regionais do comércio bilateral com os principais parceiros comerciais desses estados e, ainda, utilização de modelos mais sofisticados de painel que combinem simultaneamente estados e setores ao longo do tempo.

\section{Referências}

ARDALANI, Z.; BAHMANI-OSKOOEE, M. Is there a J-Curve at the industry level? Economics Bulletin, v. 6, n. 26, p. 1-12, 2007.

ARRUDA, E. F.; CASTELAR, P. U. C.; MARTINS, G. The J-Curve and the Marshall-Lerner Condition: Evidence for net exports in the Southern region of Brazil. Planejamento e Politicas Públicas, v. 52, n. 1, p. 17-48, 2019.

ARRUDA, E. F.; MARTINS, G. Curva J e condição de Marshall-Lerner: evidências para as exportações líquidas cearenses. Revista Economia e Desenvolvimento, v. 15, n. 1, p. 40-59, 2016.

ARRUDA, E. F.; FERREIRA, R. T. Dinâmica intrarregional do Brasil: quem dirige o crescimento industrial das regiões brasileiras? Economia Aplicada, v. 18, n. 2, p. 243-270, 2014.

BAHMANI-OSKOOEE, M; ALSE, J. Short-run versus long-run effects of devaluation: Errorcorrection modeling and cointegration, Eastern Economic Journal, v. 20, n. 4, p. 453-464, set./dez. 1994.

BAHMANI-OSKOOEE, M; BROOKS, T.J. Bilateral J-curve between US and her trading partners. Weltwirtschaftliches Archiv, v. 135, n. 1, p. 156-165, 1999.

BAHMANI-OSKOOEE, M.; FARIDITAVANA, H. Nonlinear ARDL approach, asymmetric effects and the J-curve. Journal of Economic Studies, v. 42, n. 3, p. 519-530, 2015.

BAHMANI-OSKOOEE, M.; FARIDITAVANA, H. Nonlinear ARDL approach and the J-curve phenomenon. Open Economies Review, v. 27, n. 1, p. 51-70, 2016.

BAHMANI-OSKOOEE, M.; GOSWAMI, G.G.; TALUKDAR, B. K. The bilateral J-curve: Canada versus her 20 trading partners. International Review of Applied Economics, v. 22, n. 1, p. 93-104, 2008.

BAHMANI-OSKOOEE, M.; T. KANTIAPONG. Bilateral J-curve between Thailand and her trading partners. Journal of Economic Development, v. 26, n. 2, p. 107-117, 2001.

BAHMANI-OSKOOEE, M; MALIXI, M. More evidence on the J-curve from LDCs. Journal of Policy Modeling, v. 14, n. 5, p. 641653, out. 1992.

BICKERDIKE, C.F. The instability of foreign exchanges. The Economic Journal, v. 30, n. 117, p. 118-122, mar. 1920.

BINDER, M.; HSIAO, Ch.; PESARAN, M. H. Estimation and inference in short panel vector autoregressions with unit roots and cointegration. Econometric Theory, v. 21, n. 4, p. 795 837, ago. 2005. 
BOYD, D.; CAPORALE, G.M.; SMITH, R. Real exchange rate effects on the balance of trade: Cointegration and the Marshall-Lerner condition. International Journal of Finance and Economics, v. 6, n. 3, p. 187-200, jul. 2001.

BRADA, J. C.; KUTAN, A. M.; ZHOU, S. The exchange rate and the balance of trade: The Turkish experience. Journal of Development Studies, v. 33, n. 5, p. 675-692, 1997.

CASAGRANDE, D. L.; FEISTEL, P. R.; HIDALGO, ÁlVARO B.; AZEVEDO, A. F. As elasticidades setoriais das exportações brasileiras: uma análise empírica para o período 1999 2013. Nova Economia, v. 29, n. 1, p. 193-222, 2019.

CHENG, S. Y.; WEI, J. S.; HOU, H. A cointegration analysis of purchasing power parity and country risk. International Journal of Business and Economics, v. 7, n. 3, p. 199-211, 2008.

GOMES, F. A. R.; PAZ, L. S. Can real exchange rate devaluation improve the trade balance? The 1990-1998 Brazilian case. Applied Economics Letters, v. 12, n. 9, p. 525-528, 2005.

HAHN, J.; KUERSTEINER, G. Asymptotically unbiased inference for a dynamic panel model with fixed effects when both $\mathrm{n}$ and $\mathrm{T}$ are large. Econometrica, v. 70, n. 4, p. 1639-1657, jul. 2002.

HALL, P. The bootstrap and Edgeworth expansion. New York: Springer, 1992.

IM, K. S.; PESARAN, M. H.; SHIN, Y. Testing for unit roots in heterogeneous panels. Journal of Econometrics, Washington, v. 115, n. 1, p. 53-74, 2003.

KAO, C.; CHIANG, M.-H. (2000). On the estimation and inference of a cointegrated regression in panel data. BALTAGI, B. H. (Ed.). Advances in Econometrics: Nonstationary Panels, Panel Cointegration and Dynamic Panels, v. 15, p. 179-222, 2000.

KRUGMAN P.; OBSTFELD, F. International economics: Theory and policy. Reading, Massachusetts: Addison-Wesley, 2000.

LERNER, A. P. The economics of control: Principles of welfare economics. New York: The Macmilan Company, 1944.

LEVIN, A.; LIN, C. F.; CHU, C. S. J. Unit root tests in panel data: Asymptotic and finitesample properties. Journal of Econometrics, Washington, v. 108, n. 1, p. 1-24, 2002.

LOBO, F. S. F.; Análise empirica da existência do fenômeno da curva J para a economia brasileira. 2007. Dissertação (Mestrado em Economia) - Escola de Economia, Fundação Getulio Vargas, São Paulo, 2007.

MARSHALL, A. Money, credit and commerce. London: Macmillan, 1923.

METZLER, L. A survey of contemporary economics, v. I. Homewood, Illinois: Richard Irwin, 1948.

MORAES, B. M.; TRISTÃO, P. A.; DIALLO, I.; BENDER FILHO, R. Evidências da curva J para a balança comercial do estado do Rio Grande do Sul (1999-2014). Revista de Economia, v. 41, n. 2, p. 123-150, 2015.

MORTATTI, C. M.; DE MIRANDA, S. H. G.; BACCHI, M. R. P. Determinantes do comércio Brasil-China de commodities e produtos industriais: uma aplicação VECM. Economia Aplicada, v. 15, n. 2, p. 311-335, abr./jun. 2011.

MOURA, G.; DA SILVA, S. Is there a Brazilian J-curve? Economics Bulletin, v. 6, n. 10, p. 1-17, 2005.

NARAYAN, P. K. New Zealand's trade balance: Evidence of the J-curve. Applied Economics Let- 
ters, v. 11, n. 6, p. 351-354, 2004.

NARAYAN, P. K; NARAYAN, S. The J-curve: Evidence from Fiji. International Review of Applied Economics, v. 18, n. 3, p. 369-380, 2004.

NUSAIR, S. A. The J-Curve phenomenon in European transition economies: A nonlinear ARDL approach. International Review of Applied Economics, v. 31, n. 1, p. 1-27, 2017.

NICKELL, S. Biases in dynamic models with fixed effects, Econometrica, v. 49, n. 6, p. 1.4171.426, nov. 1981.

PALMA, A. A. Política monetária e taxa de câmbio em uma pequena economia aberta: uma análise empírica para o Brasil. Nova Economia, v. 27, n. 2, 2017.

PEDRONI, P. Fully modified OLS for heterogeneous cointegrated panels and the case of purchasing power parity. Department of Economics, Indiana University, 1997. (mimeo.)

PEDRONI, P. Critical values for cointegration tests in heterogeneous panels with multiple regressors. Oxford Bulletin of Economics and Statistics, v. 61, n. S1, p. 653-670, nov. 1999.

PEDRONI, P. Panel cointegration: Asymptotic and finite sample properties of pooled time series with an application to the PPP hypothesis. Econometric Theory, v. 20, n. 3, p. 579-625, jun. 2004.

PHILLIPS, P. C. B.; MOON, H. R. Linear regression limit theory for nonstationary panel data, Econometrica, v. 67, p. 1.057-1.111, 1999.

RAMOS FILHO, H. S.; FERREIRA, M. E. P. A taxa de câmbio e os ajustes no saldo da balança comercial brasileira: uma análise setorial da curva J. Nova Economia, v. 26, n. 3, p. 887-907, 2016.

RICKMAN, D. S. Modern macroeconomics and regional economic modeling. Journal of Regional Science, v. 50, n. 1, p. 23-41, 2010.

ROBINSON, J. Essays in the theory of employment. London: Basil Blackwell, 1947.

SCALCO, P. R.; CARVALHO, H. D.; CAMPOS, A. C. Choques na taxa de câmbio real e o saldo da balança comercial agropecuária brasileira: evidências da curva J entre 1994 e 2007. Revista de Economia e Sociologia Rural, v. 54, n. 3, p. 595-610, out./dez. 2012.

SONAGLIO, C. M.; SCALCO, P. R.; CAMPOS, A. C. Taxa de câmbio e a balança comercial brasileira de manufaturados: evidências da J-curve. Economia, v. 11, n. 3, p. 711-734, set./ dez. 2010.

STOCK, J. H.; WATSON, M. W. A simple estimator of cointegrating vectors in higher order integrated systems. Econometrica, v. 61, n. 4, p. 783-820, jul. 1993.

TÜRKAY, H. The validity of Marshall-Lerner condition in Turkey: A cointegration approach, Theoretical and Applied Economics, v. 21, n. 10(599), p. 21-32, 2014.

VASCONCELOS, C. R. F. Dinâmica de curto e longo prazo da balança comercial brasileira: a validade da hipótese da curva J. Texto para discussão n. 007/2010. FE/UFJF. Programa de Pós-Graduação em Economia Aplicada, 2010.

WESTERLUND, J. Testing for Error Correction in Panel Data. Oxford Bulletin of Economics and Statistics, v. 69, n. 6, p. 709-748, 2007. 


\section{Sobre os autores}

ElanoFerreira Arruda - elano@ufc.br Programa de Pós-Graduação em Economia (CAEN) e Programa de Pós-Graduação em Economia Rural (PPGER), Universidade Federal do Ceará, Fortaleza, Ceará, Brasil.

ORCID: https://orcid.org/0000-0002-4207-2921.

GabrielMartins-gamartn@yandex.com

Universidade Federal do Ceará, Fortaleza, Ceará, Brasil. ORCID: https://orcid.org/0000-0001-6497-4291.

Os autores agradecem aos pareceristas anônimos os comentários e contribuições. O autor Elano Ferreira Arruda agradece ao Conselho Nacional de Desenvolvimento Científico e Tecnológico (CNPq) pelo apoio financeiro na realização desta pesquisa.

\section{Sobre o artigo}

Recebido em 22 de junho de 2017. Aprovado em 17 de dezembro de 2018. 


\section{APÊNDICE}

Tabela A1 PVAR para as exportações líquidas totais

\begin{tabular}{|c|c|c|c|c|}
\hline & \multicolumn{4}{|c|}{ PVAR estimado } \\
\hline & $\left(X_{i t} / M_{i t}\right)$ & $Y_{i t}$ & $Y_{i t}^{*}$ & TXCER \\
\hline$\left(X_{i t-1} / M_{i t-1}\right)$ & $\begin{array}{r}0,46^{*} \\
(0,00)\end{array}$ & $\begin{array}{l}0,01^{* *} \\
(0,02)\end{array}$ & $\begin{array}{c}0,01^{*} \\
(0,00)\end{array}$ & $\begin{array}{r}-0,005^{* *} \\
(0,02)\end{array}$ \\
\hline$\left(X_{i t-2} / M_{i t-2}\right)$ & $\begin{array}{r}0,36^{*} \\
(0,00)\end{array}$ & $\begin{array}{r}-0,01^{* *} \\
(0,04)\end{array}$ & $\begin{array}{r}-0,008^{* *} \\
(0,03)\end{array}$ & $\begin{array}{l}0,003 \\
(0,17)\end{array}$ \\
\hline$Y_{i t-1}$ & $\begin{array}{r}0,27^{*} \\
(0,00)\end{array}$ & $\begin{array}{c}0,68^{*} \\
(0,00)\end{array}$ & $\begin{array}{r}-0,06^{*} \\
(0,00)\end{array}$ & $\begin{array}{l}0,02^{* *} \\
(0,03)\end{array}$ \\
\hline$Y_{i t-2}$ & $\begin{array}{r}-0,30^{*} \\
(0,00)\end{array}$ & $\begin{array}{c}0,08^{*} \\
(0,00)\end{array}$ & $\begin{array}{l}-0,02 \\
(0,23)\end{array}$ & $\begin{array}{r}-0,03^{*} \\
(0,01)\end{array}$ \\
\hline$Y_{i t-1}^{*}$ & $\begin{array}{l}-0,17 \\
(0,17)\end{array}$ & $\begin{array}{l}-0,04 \\
(0,88)\end{array}$ & $\begin{array}{r}0,68^{*} \\
(0,00)\end{array}$ & $\begin{array}{l}-0,14^{*} \\
(0,00)\end{array}$ \\
\hline$Y_{i t-2}^{*}$ & $\begin{array}{l}0,23^{* *} \\
(0,05)\end{array}$ & $\begin{array}{r}-0,05^{* * *} \\
(0,08)\end{array}$ & $\begin{array}{r}0,24^{*} \\
(0,00)\end{array}$ & $\begin{array}{r}0,12^{*} \\
(0,00)\end{array}$ \\
\hline$T_{X C E R_{i t-1}}$ & $\begin{array}{l}-0,06 \\
(0,72)\end{array}$ & $\begin{array}{r}0,13^{*} \\
(0,00)\end{array}$ & $\begin{array}{r}0,02 \\
(0,40)\end{array}$ & $\begin{array}{r}1,18^{*} \\
(0,00)\end{array}$ \\
\hline TXCER $_{i t-2}$ & $\begin{array}{r}0,30^{* * * *} \\
(0,09)\end{array}$ & $\begin{array}{c}-0,28^{*} \\
(0,00)\end{array}$ & $\begin{array}{c}-0,16^{*} \\
(0,00)\end{array}$ & $\begin{array}{r}-0,24^{*} \\
(0,00)\end{array}$ \\
\hline$R^{2}$ & 0,82 & 0,71 & 0,98 & 0,97 \\
\hline$F(8,2002)$ & $433,69 *$ & $479,18^{*}$ & $13860,99 *$ & $10729,70^{*}$ \\
\hline Obs.: & 2040 & 2040 & 2040 & 2040 \\
\hline Grupos & 10 & 10 & 10 & 10 \\
\hline Obs.: por grupo & 204 & 204 & 204 & 204 \\
\hline
\end{tabular}

Fonte: Elaborado pelos autores a partir dos resultados obtidos.

Nota 1: Todas as variáveis estão em logaritmo.

Nota 2: $\left(X_{i t} / M_{i t}\right)$ - Exportações líquidas; $Y_{i t}-$ Renda doméstica; $Y_{i t}^{*}-$ Renda externa; $T X C E R_{i t}-$ Taxa de câmbio efetiva real.

Nota 3: P-Valor entre parêntesis. ${ }^{*}$ Significante a 1\%; ** Significante a 5\%; *** Significante a 10\%. 
Tabela A2 PVAR para as exportações líquidas (Básicos)

\begin{tabular}{|c|c|c|c|c|}
\hline & \multicolumn{4}{|c|}{ PVAR estimado } \\
\hline & $\left(X_{i t} / M_{i t}\right)$ & $Y_{i t}$ & $Y_{i t}^{*}$ & TXCER $_{i t}$ \\
\hline$\left(X_{i t-1} / M_{i t-1}\right)$ & $\begin{array}{r}0,41^{*} \\
(0,00)\end{array}$ & $\begin{array}{l}0,003 \\
(0,14)\end{array}$ & $\begin{array}{l}0,002 \\
(0,21)\end{array}$ & $\begin{array}{r}0,0002 \\
(0,81)\end{array}$ \\
\hline$\left(X_{i t-2} / M_{i t-2}\right)$ & $\begin{array}{c}0,29^{*} \\
(0,00)\end{array}$ & $\begin{array}{r}-0,002 \\
(0,35)\end{array}$ & $\begin{array}{r}-0,0001 \\
(0,94)\end{array}$ & $\begin{array}{r}0,0003 \\
(0,76)\end{array}$ \\
\hline$Y_{i t-1}$ & $\begin{array}{r}0,36^{* * *} \\
(0,08)\end{array}$ & $\begin{array}{c}0,67^{*} \\
(0,00)\end{array}$ & $\begin{array}{c}-0,07^{*} \\
(0,00)\end{array}$ & $\begin{array}{r}0,02^{* *} \\
(0,02)\end{array}$ \\
\hline$Y_{i t-2}$ & $\begin{array}{c}0,29^{*} \\
(0,00)\end{array}$ & $\begin{array}{c}0,08^{*} \\
(0,00)\end{array}$ & $\begin{array}{l}-0,01 \\
(0,31)\end{array}$ & $\begin{array}{r}-0,03^{*} \\
(0,00)\end{array}$ \\
\hline$Y_{i t-1}^{*}$ & $\begin{array}{c}0,73^{*} \\
(0,00)\end{array}$ & $\begin{array}{r}-0,003 \\
(0,90)\end{array}$ & $\begin{array}{c}0,69^{*} \\
(0,00)\end{array}$ & $\begin{array}{l}-0,14^{*} \\
(0,00)\end{array}$ \\
\hline$Y_{i t-2}^{*}$ & $\begin{array}{r}-0,50^{* *} \\
(0,05)\end{array}$ & $\begin{array}{r}-0,05^{* * *} \\
(0,07)\end{array}$ & $\begin{array}{c}0,24^{*} \\
(0,00)\end{array}$ & $\begin{array}{r}0,12^{*} \\
(0,00)\end{array}$ \\
\hline$T_{X C E R_{i t-1}}$ & $\begin{array}{r}0,49 \\
(0,19)\end{array}$ & $\begin{array}{c}0,14^{*} \\
(0,00)\end{array}$ & $\begin{array}{r}0,02 \\
(0,43)\end{array}$ & $\begin{array}{r}1,19^{*} \\
(0,00)\end{array}$ \\
\hline$T_{X C E R_{i t-2}}$ & $\begin{array}{l}-0,27 \\
(0,47)\end{array}$ & $\begin{array}{c}-0,29 * \\
(0,00)\end{array}$ & $\begin{array}{c}-0,16^{*} \\
(0,00)\end{array}$ & $\begin{array}{c}-0,25^{*} \\
(0,00)\end{array}$ \\
\hline$R^{2}$ & 0,76 & 0,72 & 0,97 & 0,98 \\
\hline$F(8,2002)$ & $212,91^{*}$ & $478,09 *$ & $13755,27^{*}$ & $10698,72^{*}$ \\
\hline Obs.: & 2040 & 2040 & 2040 & 2040 \\
\hline Grupos & 10 & 10 & 10 & 10 \\
\hline Obs.: por grupo & 204 & 204 & 204 & 204 \\
\hline
\end{tabular}

Fonte: Elaborado pelos autores a partir dos resultados obtidos.

Nota 1: Todas as variáveis estão em logaritmo.

Nota 2: $\left(X_{i t} / M_{i t}\right)$ - Exportações líquidas; $Y_{i t}-$ Renda doméstica; $Y_{i t}^{*}-$ Renda externa; TXCER $R_{i t}-$ Taxa de câmbio efetiva real.

Nota 3: P-Valor entre parêntesis. ${ }^{*}$ Significante a 1\%; ** Significante a 5\%; *** Significante a $10 \%$. 
Tabela A3 PVAR para as exportações líquidas (Industrializados)

\begin{tabular}{|c|c|c|c|c|}
\hline & \multicolumn{4}{|c|}{ PVAR estimado } \\
\hline & $\left(X_{i t} / M_{i t}\right)$ & $Y_{i t}$ & $Y_{i t}^{*}$ & $T_{X C E R_{i t}}$ \\
\hline$\left(X_{i t-1} / M_{i t-1}\right)$ & $\begin{array}{c}0,45^{*} \\
(0,00)\end{array}$ & $\begin{array}{l}0,007 \\
(0,13)\end{array}$ & $\begin{array}{r}0,01 \\
(0,00)\end{array}$ & $\begin{array}{r}-0,005^{*} \\
(0,01)\end{array}$ \\
\hline$\left(X_{i t-2} / M_{i t-2}\right)$ & $\begin{array}{r}0,35^{*} \\
(0,00)\end{array}$ & $\begin{array}{r}-0,008^{* * *} \\
(0,07)\end{array}$ & $\begin{array}{r}-0,009 \\
(0,01)\end{array}$ & $\begin{array}{l}0,002 \\
(0,32)\end{array}$ \\
\hline$Y_{i t-1}$ & $\begin{array}{l}0,26^{*} \\
(0,01)\end{array}$ & $\begin{array}{c}0,68^{*} \\
(0,00)\end{array}$ & $\begin{array}{l}-0,06 \\
(0,00)\end{array}$ & $\begin{array}{l}0,02^{* *} \\
(0,04)\end{array}$ \\
\hline$Y_{i t-2}$ & $\begin{array}{r}-0,25^{* *} \\
(0,02)\end{array}$ & $\begin{array}{c}0,08^{*} \\
(0,00)\end{array}$ & $\begin{array}{l}-0,02 \\
(0,19)\end{array}$ & $\begin{array}{r}-0,03^{*} \\
(0,01)\end{array}$ \\
\hline$Y_{i t-1}^{*}$ & $\begin{array}{c}-0,37^{*} \\
(0,00)\end{array}$ & $\begin{array}{r}-0,004 \\
(0,88)\end{array}$ & $\begin{array}{r}0,68 \\
(0,00)\end{array}$ & $\begin{array}{l}-0,14^{*} \\
(0,00)\end{array}$ \\
\hline$Y_{i t-2}^{*}$ & $\begin{array}{r}0,43^{*} \\
(0,00)\end{array}$ & $\begin{array}{r}-0,05^{* * *} \\
(0,08)\end{array}$ & $\begin{array}{r}0,24 \\
(0,00)\end{array}$ & $\begin{array}{r}0,12^{*} \\
(0,00)\end{array}$ \\
\hline$T_{X C E R_{i t-1}}$ & $\begin{array}{l}-0,22 \\
(0,24)\end{array}$ & $\begin{array}{c}0,13^{*} \\
(0,00)\end{array}$ & $\begin{array}{r}0,03 \\
(0,38)\end{array}$ & $\begin{array}{r}1,19^{*} \\
(0,00)\end{array}$ \\
\hline$T X C E R_{i t-2}$ & $\begin{array}{c}0,58^{*} \\
(0,00)\end{array}$ & $\begin{array}{r}-0,28^{*} \\
(0,00)\end{array}$ & $\begin{array}{r}-0,16 \\
(0,00)\end{array}$ & $\begin{array}{r}-0,24^{*} \\
(0,00)\end{array}$ \\
\hline$R^{2}$ & 0,80 & 0,71 & 0,98 & 0,98 \\
\hline$F(8,2002)$ & $522,35^{*}$ & $478,75^{*}$ & $13861,94^{*}$ & $10735,26^{*}$ \\
\hline Obs.: & 2040 & 2040 & 2040 & 2040 \\
\hline Grupos & 10 & 10 & 10 & 10 \\
\hline Obs.: por grupo & 204 & 204 & 204 & 204 \\
\hline
\end{tabular}

Fonte: Elaborado pelos autores a partir dos resultados obtidos.

Nota 1: Todas as variáveis estão em logaritmo.

Nota 2: $\left(X_{i t} / M_{i t}\right)$ - Exportações líquidas; $Y_{i t}-$ Renda doméstica; $Y_{i t}^{*}-$ Renda externa; TXCER $R_{i t}-$ Taxa de câmbio efetiva real.

Nota 3: P-Valor entre parêntesis. * Significante a 1\%; ** Significante a 5\%; *** Significante a 10\%. 